\title{
G-Jitter effects in Protein Crystal Growth - A Numerical Study
}

\author{
N. Ramachandran ${ }^{+}$and C. R. Baugher \\ +Universitles Space Research Association \\ NASA Marshall Space Flight Center \\ Huntsville, Al 35812, USA
}

\begin{abstract}
The impact of spacecran acceleration environment on Protein Crystal Growth (PCG) is studied. A brief overview of the Space Shuttle acceleration environment is provided followed by a simple scaling procedure used to obtain estimates of the flow and concentration field characteristics in PCG. A detailed two-dimensional numerical model is then used to simulate the PCG system response to different disturbance scenarios; viz residual $g$ effects, impulse type disturbances and oscillatory inputs. The results show that PCG is susceptible to g-jitter and is a good candidate for vibration isolation.
\end{abstract}

\section{Introduction}

Crystal growth in space benefits not only from its reduced gravity environment but also from the absence of the hydrostatic pressure which assists certain crystal growth and refinement methods. Gravity driven phenomena are thus reduced in strength, and a purely diffusive fuid behavior can be attained. In addition, past materials science experiments have shown that microgravity can also help produce larger crystals. While gravity related effects are definitely curtailed in space, they are nevertheless present to some degree due to the acceleration environment on board the spacecraft. These disturbances, collectively referred to as g-jitter, can be deleterious to certain experiments where the minimization of the acceleration level is important. Advanced vibration isolation techniques can be utilized to actively filter out some of the detrimental frequencies and help in obtaining optimum results. However, the successful application of this technology requires the detailed analysis of candidate lluids experiments to gauge their response to g-jitter and to determine their acceleration sensitivities.

Several crystal growth experiments in the Protein Crystal Growth (PCG) area, besides others, are expected to be carried out on future shuttle nights and on the spece station. The need for vibration isolation systems or components for microgravity science experiments can be expected to grow as experiments and available handware become more complex This technology will also find increased application as the science community develops an ewrareness of their specific needs relative to the environment available in manned space missions. Vibration isolation research strives to develop a microgravity environment requirement that defines tolerance limits on the allowable g-level, and provides the required technology to achieve it. This effort will assist in establishing the tolerabie acceleration levels for specific experiments. This paper is directed towards modeling PCG with the following objectives in mind.

l. To computationally determine vibration sensitivity of Protein Crystal Growth Experiments.

2. Determine if these experiments can benefit from vibration isolation techniques.

3. Provide realistic requirements for vibration isolation technology.

\section{The Space Shuttle Acceleration Environment}

The Orbiter Structural coordinate system shown in Fig. 1. The accelerations experienced in a manned orbiting space laboratory are loosely classified as quasi-steady, oscillatory, and transient. The quasi-steady classification, by convention, is assigned to accelerations with frequency below about $0.01 \mathrm{~Hz}$. This encompasses accelerations due to atmospheric drag, gravity gradient effects, and rotational forces and is estimated [1] and measured [2,3] to be on the order of $10^{-6} g_{0}$. The drag contribution varies with the orbital frequency of about $10^{-4} \mathrm{~Hz}$. The operation of machinery, control thrusters, solar panels, human activity, etc., contribute to higher frequency accelerations.

Typical acceleration data taken on STS 47 (launched Sept. 1992) are shown in Fig. 2 as a power spectral density plot. This plot represents the environment during nominal crew activity and is characterized by distinct frequency peaks in the 1-10 $\mathrm{Hz}$ range that correspond to the Orbiter structural modes. The term nominal crew activity is used to indicate a time period when no significant acceleration sources such as vehicle maneuvers, water dumps, satellite launches and crow exercise are present. The measured ecceleration magnitudes are generally found to vary with the level of crew activity. Fig. 3 shows an ecample of the difference in levels during periods of crew sleep, nominal crow activity, and crew exercise on a bicycle ergometer taken on the STS-40 mission [4].

The data in each plot is a PSD calculation performed on $\mathbf{5 0}$ seconds of raw SAMS data and presented in units of Micro-g/Hz ${ }^{1 / 2}$. The RMS value for the data on each chart is shown in the figure. Acceleration levels in time vary from $10^{-4}$ to $10^{3} \mathrm{~g}_{0}$. The SAMS senser, located in rack 5 in the Spacelab module, recorded data at 25 samples/sec with a 5 Hz low pass filter. An important characteristic of the $g$-jitter environment is that the oscillatory and transient sources tend to excite Orbiter and payload structural modes. Because of this, the efrects of a high magnitude transient source may be felt by an experiment in the form of 

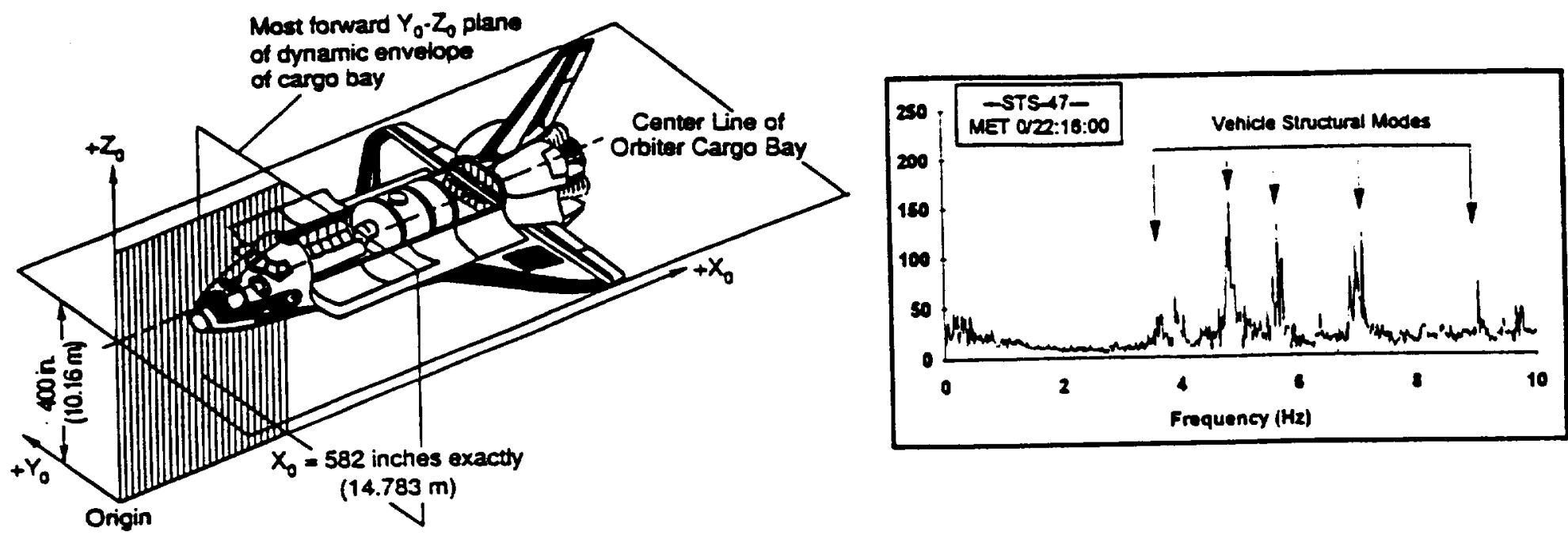

FIG. 2 MYPICAL LOW FREQUENCY STS STRUCTURAL MODES

FIG. 1 THE ORBITER STRUCTURAL COOROINATE SYSTEM

$$
\left(X_{0}, Y_{0}, z_{0}\right)
$$

CREW SLEEP PERIOD - MET 6/13:20
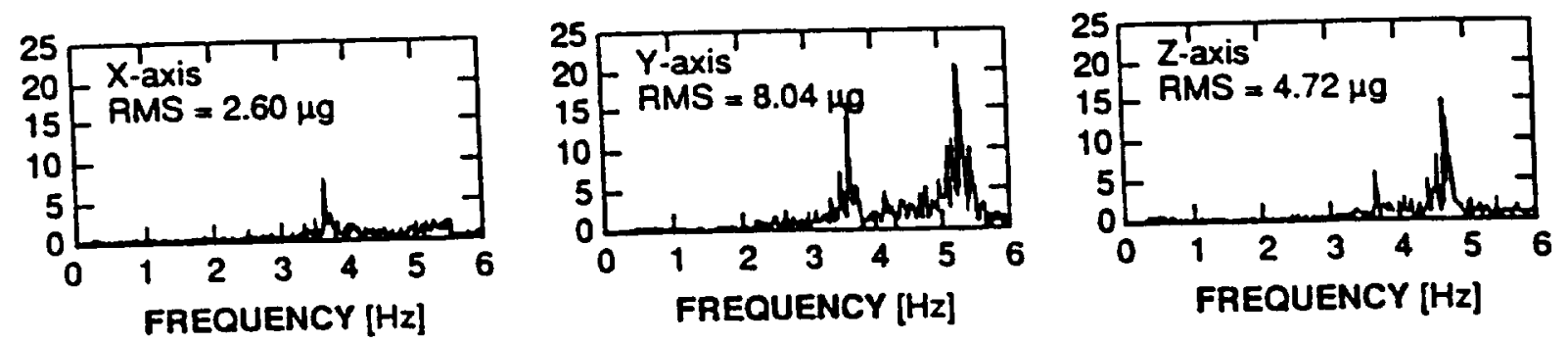

ROUTINE CREW ACTIVITY - MET 3/01:03


SPACELAB ERGOMETER EXERCISE - MET 2/07:36
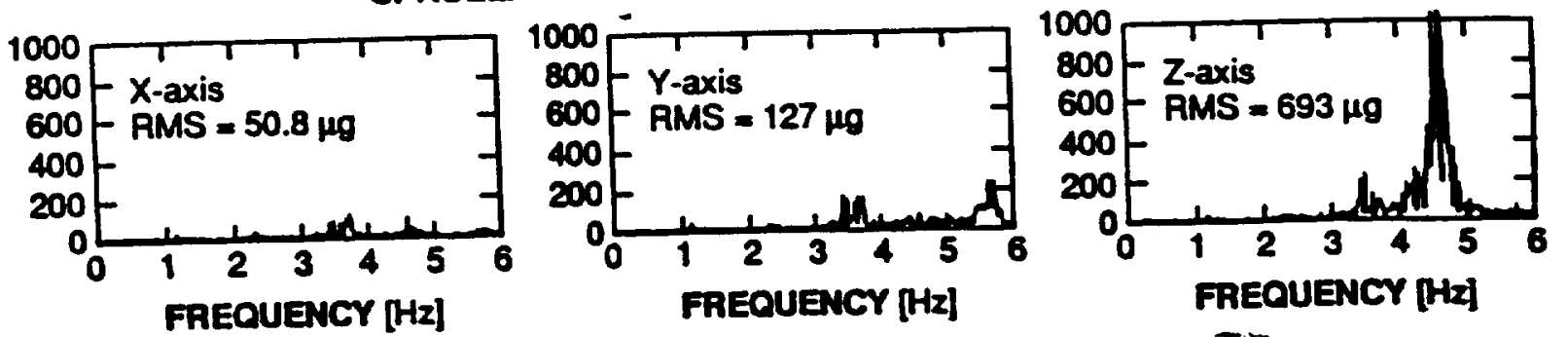

FIG. 3 POWER SPECTRAL DENSTY OF THE ACCELERATION EMMROMENT ON STS-40 - SPACELAB MOOULE UNTS OF MAL 
damped ringing for some time after the initial ovent occurred [4]. The 3.5, 4.7 and $5.5 \mathrm{~Hz}$ components are all related to the excitation of structural modes by exercise activity and occasional thruster firings. Note the change of scales in the graphs. Even during the sleep period, the observation is dominated by the vehicle structural modes, but the general level has decreased by an order of magnitude. An example of the excitation of structural modes by an oscillatory source is the $17 \mathrm{~Hz}$ signal (not shown in Fig. 2). The KU-band communications antennae on the Orbiters dithers at $-17 \mathrm{~Hz}$ to prevent stiction of the gimbal. This dither frequency tends to excite a $17 \mathrm{~Hz}$ Orbiter mode. During USMP-1, recorded not only the $17 \mathrm{~Hz}$ signal, but also first through fourth harmonics at $34,51,68$, and $85 \mathrm{~Hz}$ The most interesting feature of this signal is the extreme variability of its signature. Acceleration levels while the antenna was operating varied by an order of magnitude. The source of the variability is presently unknown, but it seems likely that it is related to the pointing angles of the system.

\section{Protein Crystal Growth}

Several proteins have been hown during past shuttle missions with the aim of growing bigger and better crystals. Protein crystal growth in microgravity benefits from the following advantages.

1. The free suspension of the protein in the growth medium (due to diminished gravity) promotes uniform crystal growth and eliminates container interface effects.

2. Convection offects are minimized and diffusion controlled crystal growth can be realized.

3. Internal stresses in the complex biological macromolecules are eliminated due to the reduced hydrostatic pressure environment. This helps in improved intemal order of the grown crystal and prevents the collapse of the big complex molecules.

The data collected from past shuttle missions have all indicated that microgravity can be offectively utilized to obtain higher quality protein crystais. The space grown crystals tend to be significantly better than the best earth grown samples and thus are ideal for protein crystallography. However, past experience has also shown that the microgrevity environment on the Space Shuttle can sometimes yield unpredictable reaults in PCG. Poor crystal quality due to crecking, stunted erystal growth, multiple and some times showers of small crystals have been observed with certain PCG experiments. The causative factors for these effects have not all been completely understood. It is generally agreed however, that crow activity and g-jitter all play some role in this crystal degradation process.

In any PCG experiment the solution transport within the growth medium and the crystal surface attachment kinetics play key roles in determining the erystal growth rate. With most small molecule crystals, solution transport is the rate limiting step. In such situations, forced corvection in the solution will increase the growth rate up to a certain point beyond which surfece kinetica becomes the controlling factor. Experiments by Pusey of al. [6] using tetragonal lysozyme have shown that forced flow rates of $30-40 \mu \mathrm{m} / \mathrm{s}$ slow and eventually stop the growth of $10 \mu \mathrm{m}$ cystals. More recent experiments by Pusey [7] suggest that this growth cessation is present even at lower flow rates but the growth declines over a much larger time then at the higher flow rates. In the experiments [7], even very small velocities of the order of $\approx 2.5 \mu \mathrm{m} / \mathrm{s}$ were seen to irreversibly terminate the $(110)$ tace growth of tetragonal bysazyme crystals. Corroborating results have been reported by Nyce and Rosenberger [8], who further showed that this growth cessation is not observed in the growth of orthorhombic lysozyme crystals. In their studies, Grant and Sevilie [9], proposed and subsequently disproved based on theoretical analyses a host of mechanisms that may account for the growth cessation behavior. The inclusion of contaminants from solution was hypothesized as the probable cause of this behavior. However, as mentioned in [7]. this mechanism does not explain the absence of similar effects in the growth of orthorhombic lysozyme [8]. Thus for some crystals at least, even small convective flows are deleterious for growth of the crystal. The exact mechanism for this effect is as yet not fully understood.

\section{Time Scales and Boundary Layers}

As a first step in the modeling process, estimates of the system time scale and boundary layer thickness have to be determined. Hens egg protein, lysozyme, is chosen for modeling purposes because it is a commonly available protein which is well characterized and and frequently used as a benchmark to test out new growth procedures, analysis etc. Estimates of its physical properties are shown in table 1.

Table 1: Propertles of Lysozyme

\begin{tabular}{|l|c|}
\hline Density, $p,\left(g / \mathrm{cm}^{3}\right)$ & 1.2 \\
Density difference, $\Delta \rho\left(g / \mathrm{cm}^{3}\right)$ & 0.01 \\
Diffusivity, $D\left(\mathrm{~cm}^{2} / \mathrm{s}\right)$ & $10^{-6}$ \\
Knematic viscosity, $v\left(\mathrm{~cm}^{2} / \mathrm{s}\right)$ & 0.01 \\
Crystal Length, L (cm) & 0.1 \\
Crystal Radius, a (cm) & 0.05 \\
Grashof Number, $G r(1 \mathrm{go})$ & 81.67 \\
Schmidt Number, Sc ( v/D) & $10^{4}$ \\
\hline
\end{tabular}

The time scale of flow (fluid motion) can be estimated for both convective and diffusion dominated transport in terrectrial experiments, the now is typically dominated by comection and the governing time scale is denoted as ${ }^{\mathrm{c}}$ dolined as

$$
\tau_{c}=8 / v
$$

where $\delta$ is the boundary layer thickness defined as

$$
\delta=L(S c G r)^{-1 / 4}
$$

and the Grashof number is defined as 


$$
G r=g(\Delta \rho / \rho)\left(L^{3} / v^{2}\right)
$$

Therefore using the physical properties listed in table 1 estimates can be drawn for $\delta$ and $\varepsilon$ at different gravity levels. These are listed in table 2.

Table 2: TIme scales and Boundary layer extents

\begin{tabular}{|c|c|c|}
\hline 9 - lovel & $\delta(\mathrm{cm})$ & T (sec) \\
\hline $\begin{array}{l}1 g_{9} \\
10^{-9} g_{0} \\
10^{-2} g_{0} \\
10^{-3} g_{0} \\
10^{-4} g_{0} \\
10^{-5} g_{0} \\
10^{-6} g_{0}\end{array}$ & $\begin{array}{l}33.26 \times 10^{-4} \\
59.15 \times 10^{-4} \\
105.2 \times 10^{-4} \\
187.06 \times 10^{-4} \\
0.03326 \\
0.0591 \\
0.1052\end{array}$ & $\begin{array}{l}1.1 \times 10^{-3} \\
3.50 \times 10^{-3} \\
1.107 \times 10^{-2} \\
3.50 \times 10^{-2} \\
0.1106 \\
0.350 \\
1.1079\end{array}$ \\
\hline
\end{tabular}

From table 2, it is evident that the boundary layer thickness is only of the order of $33 \mu \mathrm{m}$ for earth grown crystals but is of the order of the crystal radius, which is incidentally also the diffusion length scale, at a g-level of $10^{-5} \mathrm{~g}_{0}$. The length scale thus suggests that diffusion limited crystal growth can be achieved at a residual g-level of $10 \mu$ g. This remains to be verified by detailed fluid modeling. The diffusion time scale can then be evaluated as

$$
\tau_{c}=a^{2 / v}=0.25 \mathrm{sec} \text {. }
$$

This implies that fluid nows can be initiated by excitations with time scales $\geq 0.25 \mathrm{sec}$ or by frequencies $\leq 4 \mathrm{~Hz}$. As discussed in an earlier section, the acceleration environment on the Space Shuttle contains several distinct vehicle structural modes in the $1.10 \mathrm{~Hz}$ range which can affect the fluid flows in protein crystal growth. The short time scaie is due to the extremely small crystal size and as a result it takes but a small fluid velocity to traverse this dimension. One result of this lluid transport is the destruction of the existing solute gradient adjecent to the crystal. Thus an already established diffusional gradient is completely swept away by the fluid. The time scale for diffusion limited solute transport can be estimated as

$$
\tau_{s}=a^{2} / D=2500 \mathrm{sec} \text {. }
$$

and thus it takes nearly 41 mins. for re-extabllshing the concentration gradient

\section{Order of Magnitude Analysis}

The magnitudes of the oscillatory disturbances that are of consequence to PCG can also be cuimated by implementing a simple Order of Magnitude Anabycis (OMA) of the equations describing the system. The analysis involves choosing appropriate scaling factors for length, velocity, concentration, and other variables of importance to the experiment, while determining the dominant terms in the governing equations describing the system. Estimates of fuid sensitivity as a tunction of acceleration amplitude and frequency are obtained, and these estimates can be used as a preliminary guide to more detailed computations. A representative OMA curve for proteins is shown in Fig. 4 [10].

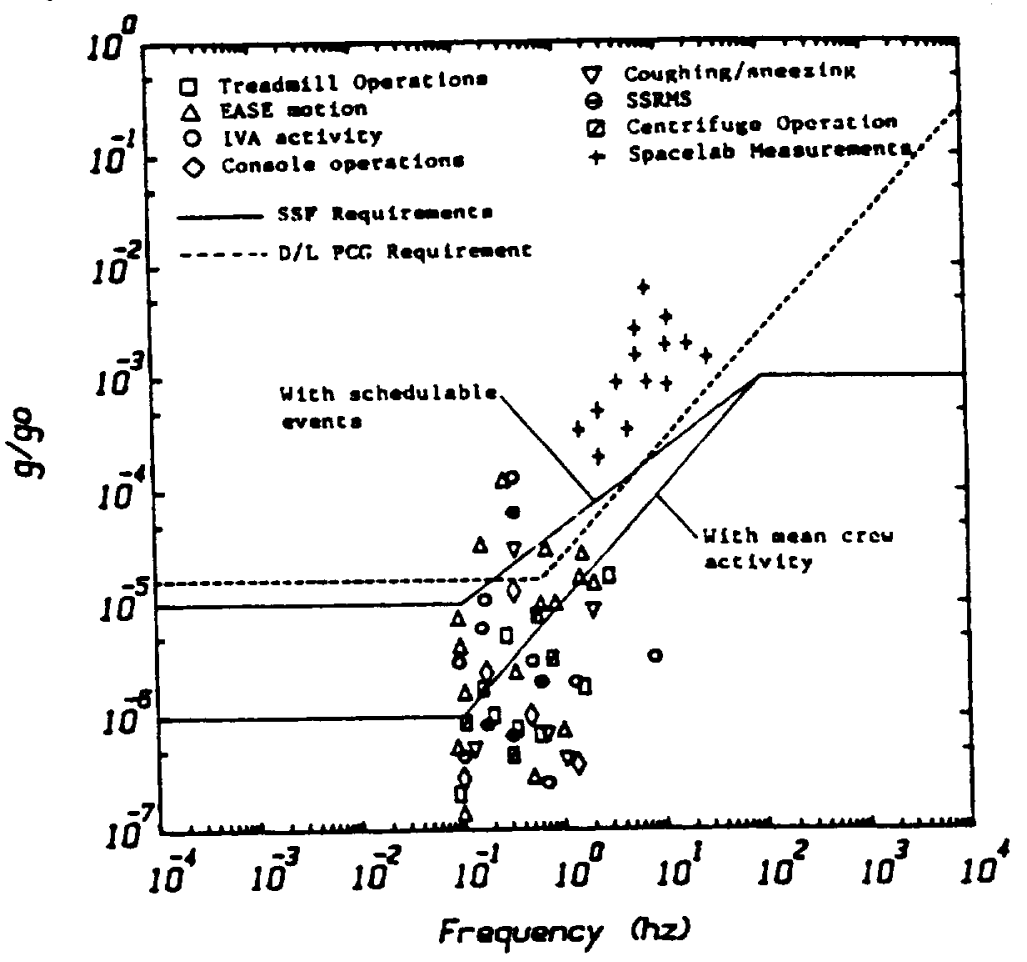

FIG. 4 OMA CURVE FOR PROTEIN CRYSTAL GROWTH

The analysis shows that the proposed spece station mierogravity environment would be conducive towards achieving this goal. PCG on board other manned vehicles on the other hand, would have to resort to other means to achieve the required acceleration emvironment. Vibration isolation technology can be used to fitter harmful trequencies and thus minimize the resulting comvective effects. Current technology using active vibretion devices can filter frequencies up to approximately $0.1 \mathrm{~Hz}$ and thus hold promise in this area. It should be pointed out that OMA cotimates are based on a very simpte model of the phyrical processes and probably over extimate the comvective transport The model is however expected to provide correct trends and perhaps quantitative information within an order of magnitude accuracy. The level of accuracy can evaluated by detailed CFD modeling.

\section{Fluids Modeling}

The 2-0 computational model is shown in Fig. 5. A cryctal of dimensions $L=2 a=0.1 \mathrm{~cm}$ is adopted for the calculations with the walls placed $5 a$ and $4 a$ to the side and below the erystal, respectively. Coding detaik are given in [5] The erystal is modeled in planar two dimensions assuming an axis of symmotry. Comparisons of planar and oxisymmetric calculations show that some differences exist in the two computed flow and solute fields. In an edsymmetric situation, the effects of the malls ere 
attenuated whereas in a Cartesian system the wall effects are fett in some measure. The actual crystal growth process is typically of the order of $1-2 \mathrm{~mm} /$ day and hence is treated as a quasi-stendy phenomenon. This implies that even though time accurate calculations are carried out to record the fluid response to time varying disturbances, the actual growth of a cystal phase is not modeled. This is a reasonable assumption considering the disparity between the respective time scales. No slip boundary conditions are applied on the cystal walls and on the computational domain $x=L$ and $y=0$. The understanding of the kinetics of the protein crystal growth process and its effect on surface flow characteristics is still in its infancy and hence the no slip velocity condition is imposed at the crystal wall.

\section{Residual-g Effecto}

As a first step, the fluid response to terrestrial gravity $\left(1 g_{0}\right)$ is calculated. An $81 \times 51(x, y)$ staggered grid is used in the calculation. Scaling analysis has shown that the boundary layer thickness in this instance is about $33 \mu \mathrm{m}$. The grid spacing is chosen such that the distance from the crystal wall to the nearest grid point is $5.067 \mu \mathrm{m}$, so that there are about 6 grid points within the solute boundary leyer. Results for this case are shown in Fig. 6. A maximum tangential fluid velocity of $70 \mu \mathrm{m} / \mathrm{s}$ is calculated adjacent to the crystal face. This compares well with an estimate of $90.35 \mu \mathrm{m} / \mathrm{s}$ obtained from scaling analysis where the maximum velocity is given by the expression $(\mathrm{Gr} / \mathrm{Sc})^{1 / 2}(\mathrm{v} / \mathrm{L})$.

The equi-concentration contours or isomers for this case are also shown in Fig. 6. The steep concentration gradients next to the enstal are apparent from the figure.
The boundary layer thickness is $=0.12 \mathrm{~mm}$. The mass transfer into the crystal is characterized by the average Sherwood number defined as

$$
\text { Sh }=\int(\partial c / 2 n) \text { wall }
$$

where $n$ denotes the local normal to the wall. The Sherwood number is averaged over the entire crystal ( $L \times 2 a)$. For 1 $g_{0}$, the calculated $S h$ is 16.4 , compared to $S h=1.0$ for pure diffusion limited grouth.

The fluid response to a parametric variation of the $\mathrm{g}$ level $\left(10^{-2} g_{0} 10^{-3} g_{0,1} 10^{-1} g_{0}, 10^{-5} g_{0}\right.$, and $\left.0 g_{0}\right)$ is plotted in Fig. 7 as isomer distributions. The gradual thickening of the solute boundary layer is clearty visible as the g-level is decreased. The respective Sherwood numbers are also indicated in the figure. The $\mathrm{Sh}$ values characterize the strength of convection within the cell and are seen to diminish as the gravity level is reduced. The diffusion limited case $(g=0)$ represents ideal crystal growth conditions and provides a reference point from which to compare the other growth scenarios. For example, at $g=$ $10^{-5} g_{0}$ (typical of the residual gravity level in space) only minor isomer distortions can be discerned from the figure and the Sherwood number is close to unity. Diffusion limited grouth conditions are approached at this low gravity level as predicted by scaling analysis.

It is to be noted that the isomer contours for $g=0$ show the effect of the computational domain by being drawn closer together near the bottom of the domain (below the cystal) than in the upper regions (above the crystal). Also, in order to maintain mass balance, the upward convection

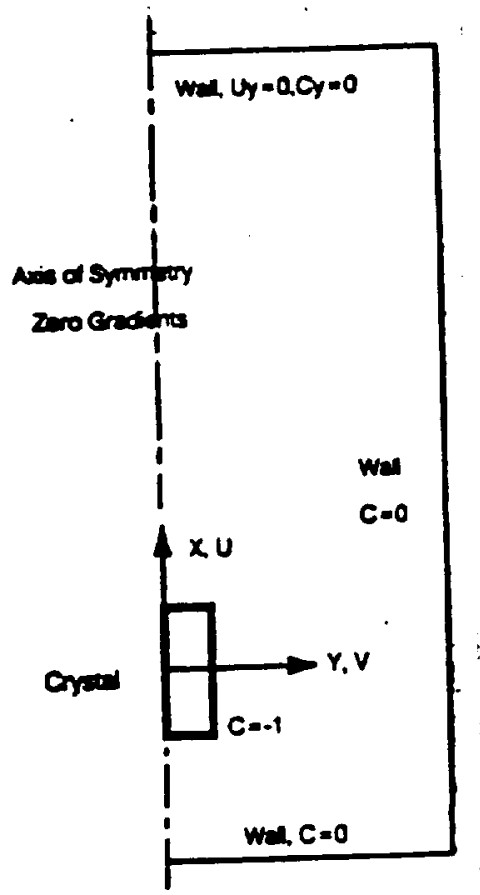

FIG. 5 2-D PCGMODEL
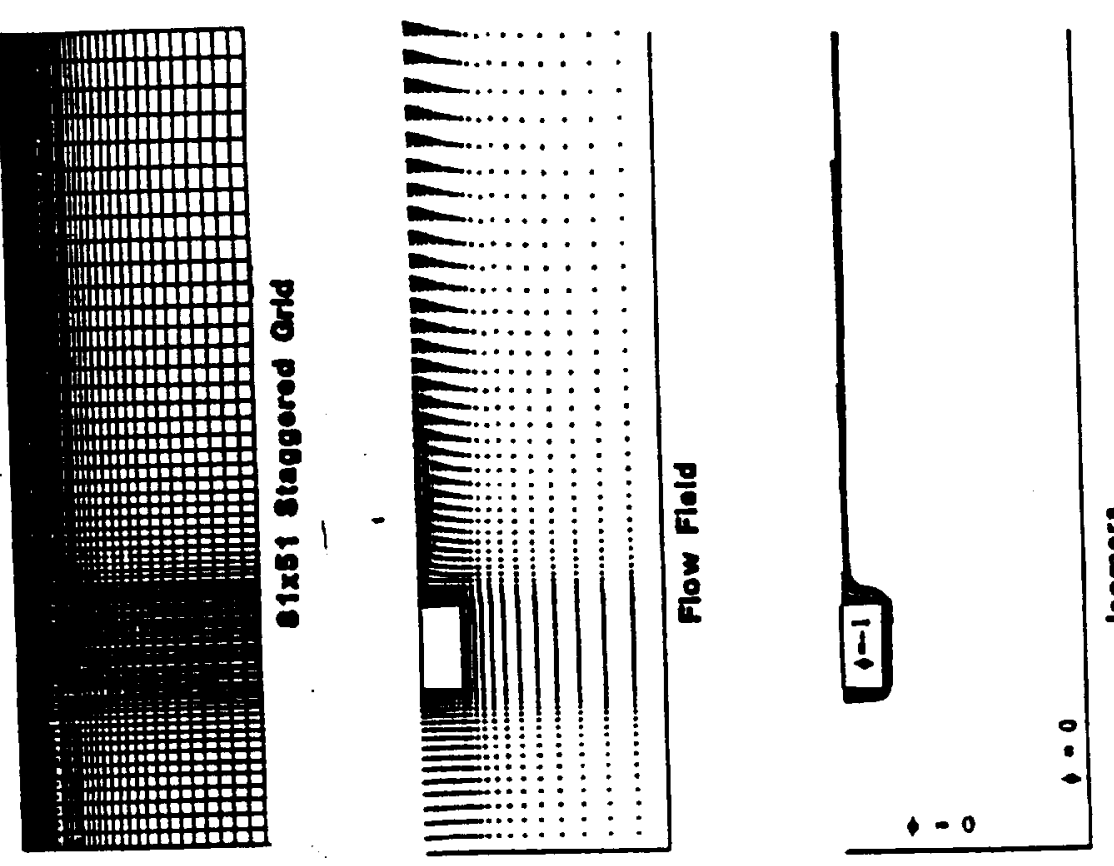

FG. 6 FUID RESPONSE TO TERRESTRLL GRAVITY 


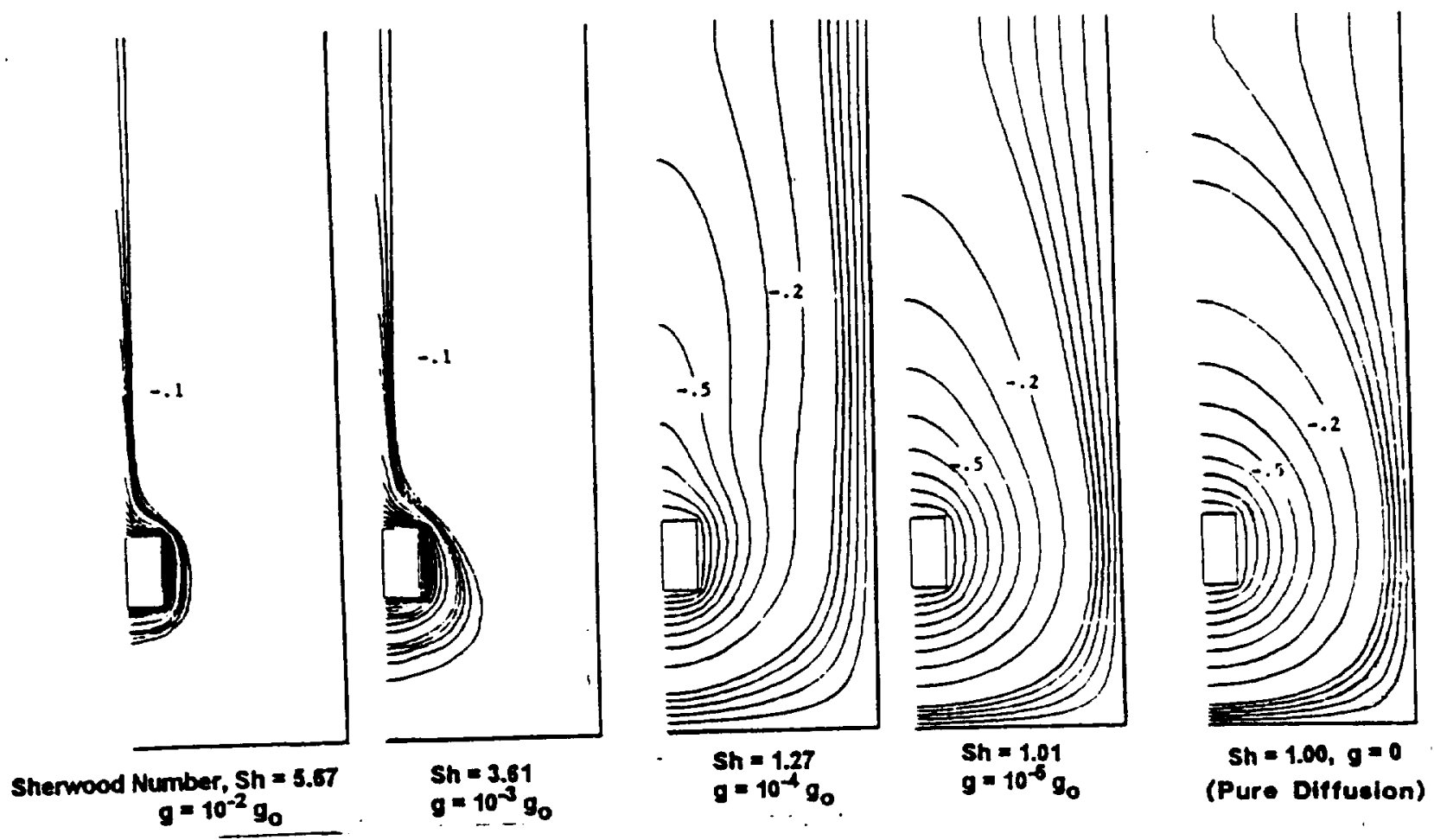

FIG. 7 SYSTEM RESPONSE TO A PARAMETRIC VARLATION IN gLEVEL (ISOMER CONTOURS)

plume in the system forces fluid entrainment and dowmward flow in the vicinity of the side wall. These effects are artifacts of the computational domain. The main interest however, is the fluid now in the vicinity of the erystal itself. These axial hows are shown in Fig. 8 for the different residual $g$ levels simulated. As the g-level is dropped, the velocity peaks are attenuated and shifted to the right as the boundary layer thickens.



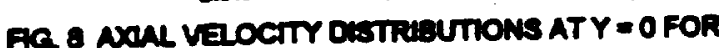
OUFERENT OLEVELS

Impules type disturbances

Transient events like thruster bums to achieve a certain night attitude are more predictable than random impulse type disturbances due to crew activity like opening and closing of lockers, the action of control relays to activate equipment or control experiments and astronauts bumping into equipment etc. Impulse strengths of up to $10^{-2} g_{0}$ have been measured during past shuttle flights. In order to study fluids response to these disturbances, three specific events are simulated.

\section{Singto Impulse disturbanco}

i. Ten seconds of zero gravity, Pure Dn conditions.

ii. One second impulse of strength: Case $A: 10^{-2} g_{0}$ and Case B: $10^{-3} g_{0}$.

11. Calculations carried out for 600 seconds (10 minutes) after impulse with zero gravity.

Fig. 9 shows the isomers and stream hunction plots at different times in the calculations for case A The onset of the now is immediate after the impulse and the flow development is complete 1 sec after the impulse. A cockwise rotational cell is extablished in the oystem. No disturbance effects are howmer mident in the concentration field at this time. The maximum velocity right next to the crystal is about $4 \mu \mathrm{m} / \mathrm{s}$ and the maximum global velocity (entire computational domain) is about $40 \mu \mathrm{m} / \mathrm{s}$. A time history of the global maximum velocity is shown in Fig. 10. There is a sharp spike in the how which rapidly decays as shown in the figure. The transient $4 \mathrm{\mu m} / \mathrm{s}$ frow adjacent to as the crystal hardly disturbs the solute distribution because in 11 exc only a distance of $4 \mathrm{\mu m}$ is traversed by the flow adjacent to the $100 \mathrm{~mm}$ cryatal fece. Some isomer disturbances are evident 100 secs after the impulse

"disturbance and clearly noticenble variations are seen 10 mins after impact These veriations are due to the circulation in the fiow ficld set up by the impulse that lingers for a fairty long time due to fluid inertia and the absence of any significant damping effects. This circulation eventually 



looment strem Function

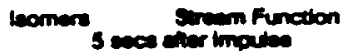

Lomere stream Functon
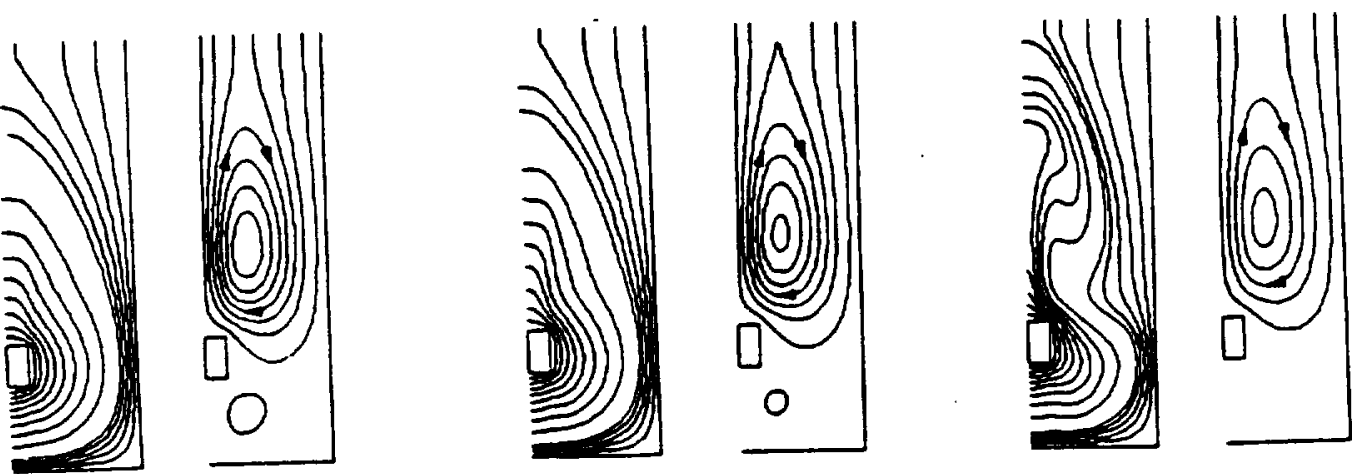

teomern sonem function

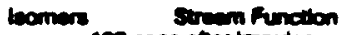

bermers surem Function

FI6.9 FLUID RESPONSE TO AN MPULSE DISTURBANCE - STREAM FUNCTION ANO ISOMER DISTRIBUTTONS (MUPULSE OF $10^{2} \mathrm{~g}_{0}$ FOR 1 SECOND)

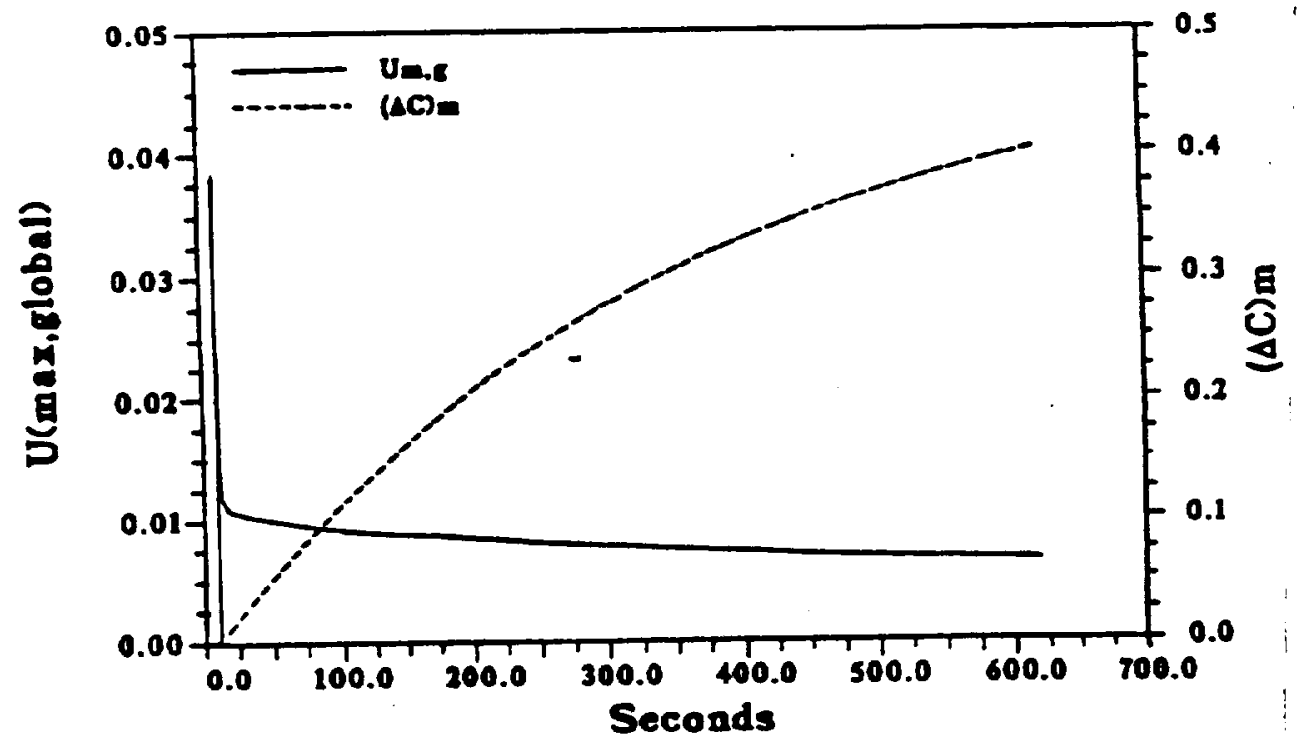

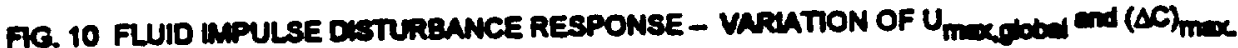


draws the isomers as shown in the figure. Fig. 10 also shows the maximum departure of concentration in the system from the reference case $(g=0)$ as a function of time. The disparity between the fow and solute responses is strikingly evident from this figure. In fact, for the solute field, $\Delta C_{\max }$ is still showing a growing trend 10 mins after the impulse. Results for an impulse of $10^{-3} g_{0}$ show similar results with the system response attenuated by an order of magnitude.

\section{Double Impulse disturbances}

The disturbance scenario for this part of the simulation is outlined below.

I. Ten seconds of zero gravity, Pure $D /$ conditions.

ii. One second impulse of strength $10^{-3} \mathrm{~g}_{0}(+x$ direction).

iii. 1 second of zero gravity after impulse.

iv. One second impulse of strength $10^{-3} g_{0}(-x$ direction).

v. Calculations carried out for 600 seconds (10 minutes) after second impulse with no gravity.

A pulse/anti-puise type disturbance is interesting because the mean $g$-level imparted to the system is zero and yet there exists net transport in the system response. Similar to the single impulse response, the flow responds almost instantaneously setting up a clockwise circulation after the first pulse and a complete reversal after the antipulse. Maximum velocities of $3.72 \mu \mathrm{m} / \mathrm{s}$ and $3.69 \mu \mathrm{m} / \mathrm{s}$ are recorded due to the first and second impulses respectively. Ten minutes into the computation, significant isomer distortions due to the residual flow circulation in the system is noticed. So, in essence, the flow has no memory of the first impulse but retains the memory of the second impulse. Similar results have been reported from computations in other configurations.

\section{Oscilatory disturbances:}

The system response characteristics to an oscillatory disturbance frequency of $3.183 \mathrm{~Hz}(20 \mathrm{rad} / \mathrm{s})$ and amplitude of $10^{-3} g_{0}$ are shown in Fig. 11. This frequency is close to a structural mode of $3.5 \mathrm{~Hz}$ and also to the $2.5 \mathrm{~Hz}$ noticed in SAMS data during treadmill operations on the Space Shuttle. The figures show complete now reversal during each cycle. Fig. 11 shows the isomer and stream function plots during the 5th cycle of g-jitter and are representative of a periodic behavior attained within the system. The calculations show that the solute neld is relatively unaffected by the disturbance but the flow field displays a 3 $\mathrm{Hz}$ response as predicted by scaling arguments. This implies that a protein molecule is constantly being jiggled by the oscillatory disturbance. Whether such fluid motion is deleterious to crystal growth is unclear. Time history plots of $\mathrm{Sh}$ and $(\Delta C)_{\max }$ also show trequency modulated response, but the variation magnitudes are very low, $-10^{-5}$.
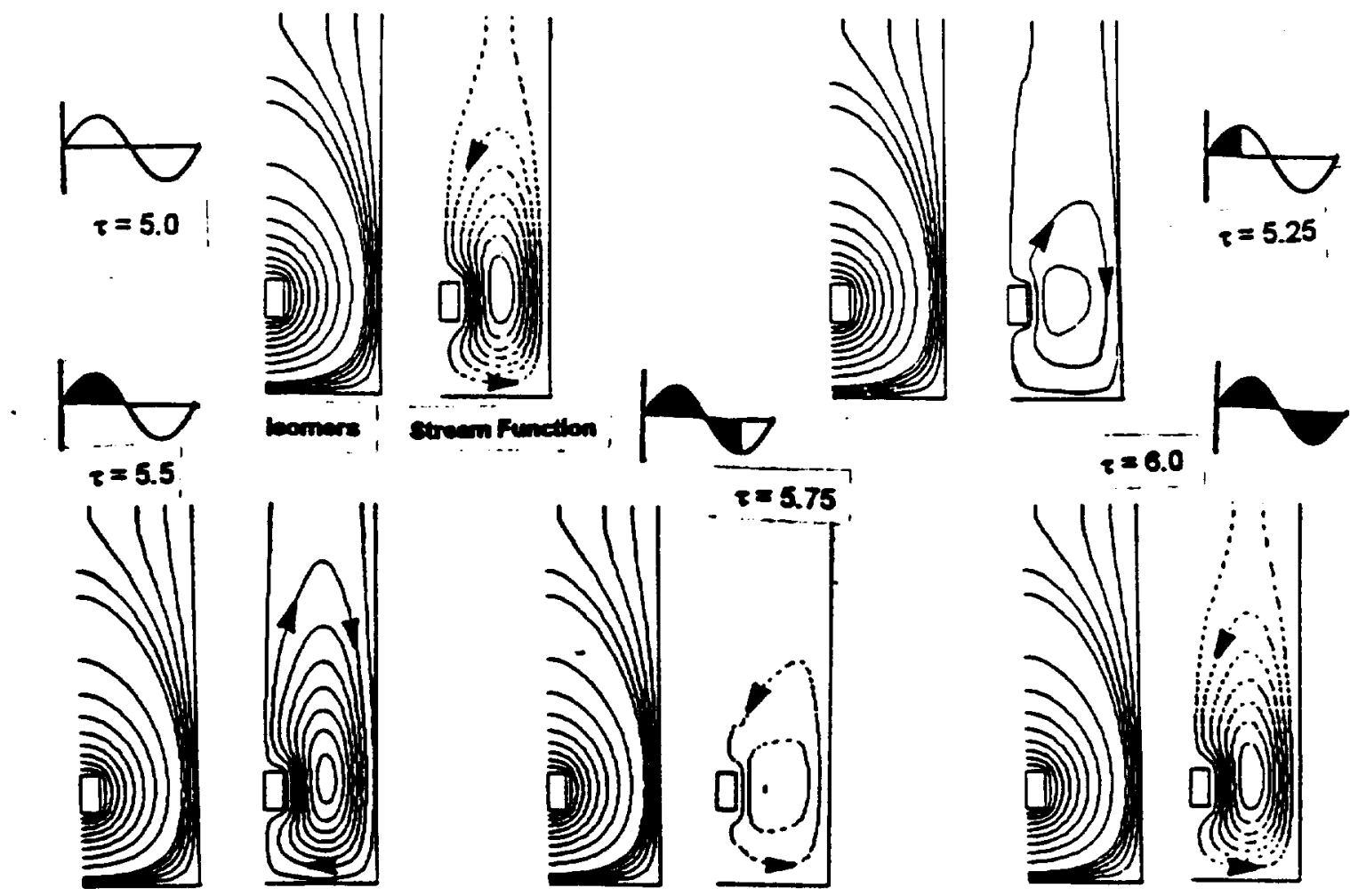

$t=5.25$

FIG. 11 FUID RESPONSE TO AN OSCIUATORY DISTURAAMCE - STREAM FUNCTION AND ISOMER DISTRIBUTIONS (FREQUENCY $=20$ redk, MIPUTUDE $=10^{3} \mathrm{DO}$ ) 


\section{Conclusions}

The salient results from the investigation are as follows:

1. G-jitter dominates the spacecran acceleration emvironment. It is comprised of a myriad frequencies and displays no preferred orientation. The g-jitter magnitudes can be as high as 1 millig $\left(10^{-3} g_{0}\right)$.

2 Impulse type disturbances are random in nature and hence unpredictable. The solutal field response to impulsive forces is especially long term and considerable. Impulse type disturbances are also deleterious to PCG in other respects e.g. drop dislodgment, multiple crystals, crystal cracks etc. It is therefore prudent to take remedial measures to safeguard against their pernicious effects on materials processing.

3. PCG observations and analyses indicate susceptibility to g-jitter.

4. Calculations show the PCG flow field is susceptible to $1-10 \mathrm{~Hz}$ frequency range.

5. PCG is a good candidate for Vibration Isolation. Current vibration isolation system can filter up to $0.1 \mathrm{~Hz}$ Passive systems can also filter down to this frequency level.

6. A passive Isolation System for PCG is a first recommendation.

\section{Acknowledgments}

The analysis of the Space Shuttle acceleration environment was done under the Acceleration Characterization and Analysis Project (ACAP) supported by the NASA Otfice of Life and Microgravity Sciences and Apolications. The process modeling work wes supported by the NASA Office of Advanced Concepts and Technology.

\section{References}

1. Hamacher, H. and U. Merbold., Microgravity environment of the Materia Science Double Rack on Spacelab-1," J. Spacecrat, Vol. 24, No. 3, pp. 264-269, 1987.
2 Blanchard, R. C., Nicholson, J. Y., and Ritter, J. R., Preliminary OARE Absolute Acceleration Measurements on STS-50," NASA TM 107724, Feb. 1983.

3. Baugher, C. R., Accoleration Characterization and Anclysis Project (ACAP) - 1992 Annual Report, NASA Marshall Space Flight Center, 1993.

4. Baugher, C. R., and Ramachandran, N., An Overview of the Space Shuttle Acceleration Environment. Presented at the SPIE International Symposium on Aerospace Sensing, Orlando, Florida, April 4-8, 1994.

5. Ramachandran, N, Baugher, R. C., and Rogers, M, J, B., "Acceleration Environment of the Space Shuttle and its Impact on Thermo-Solutal Fluid Mechanics," ASME Winter Annual Meeting, New Oreans, Nov. 28 - Dec. 3. AMD-Vol. 174, FED Vol. 175, pp. 155-171, 1993.

6. Pusey, M., Witherow, W., and Naumann, R., "Preliminary Investigations into Solutal Flow about Growing Tetragonal Lysozyme Crystals", Joumal of Crystal Growth, Volume 90, 1988, pp. 105-111.

7. Pusey, M., Fourth Intemational Conference on Crystallization of Biological Macro-molecules, Aug. 18 23, 1991, Freiburg, Germany.

8. Nyce, T., and Rosenberger, F., Joumal of Crystal Growth, 110, 1991, pp. 52.

9. Grant, M. L, and Seville, D. A, Joumal of Crystal Growth, 108, 8, 1981.

10. Naumann, R., Private Communication, 1990. 